\title{
Optimization and Kinetic Modelling of Total Phenols and Flavonoids Extraction from Tilia cordata M. Flowers
}

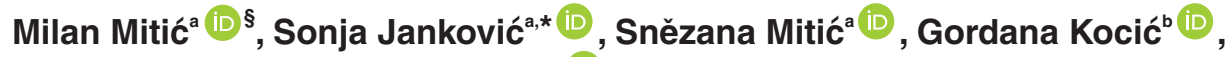 \\ Pavle Maškovićc ${ }^{(D)}$ and Dragutin Đukićc \\ ${ }^{a}$ Department of Chemistry, Faculty of Sciences and Mathematics, University of Niš, Višegradska 33, 18000 Niš, Serbia. \\ ${ }^{b}$ Faculty of Medicine, University of Niš, Dr Zorana Đindicá 81, 18000 Niš, Serbia. \\ ${ }^{c}$ Faculty of Agronomy, University of Kragujevac, Cara Dušana 34, 32000 Čačak, Serbia.
}

Received 8 May 2020, revised 30 September 2020, accepted 16 October 2020

\begin{abstract}
The main goal was to optimize and establish the kinetics and the thermodynamics of the extraction process. An investigation into the effects of ethanol concentration $(0-100 \%)$, liquid to solid ratio $\left(30-60 \mathrm{~mL} \mathrm{~g}^{-1}\right)$, extraction temperature $\left(25-65^{\circ} \mathrm{C}\right)$, and extraction time (40-200 $\mathrm{min}$ ) on the extraction of total phenols (TP) and total flavonoids (TF) from linden (Tilia cordata M.) flowers was performed using single-factor experiments. Experimental results showed that extraction conditions had a significant effect on the extraction of phenolic compounds. The optimized conditions were $50 \%$ ethanol, liquid to solid ratio $60 \mathrm{~mL} \mathrm{~g} \mathrm{~g}^{-1}$ for $120 \mathrm{~min}$ at $55^{\circ} \mathrm{C}$,

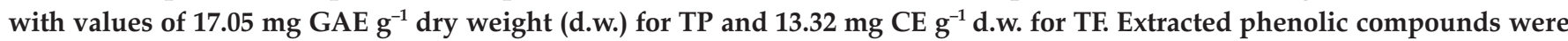
analyzed by HPLC. The antioxidant activity of the extracts was evaluated by DPPH and ABTS assays. The applicability of different mathematical models (model based for the unsteady diffusion through the plant material, model based on the film theory and model of Ponomaryov) to describe the kinetics of the extraction process of TP and TF from linden flowers was studied as well. The mathematical models applied showed a good agreement with the experimental results, which allows their application in modelling and optimizing the solid/liquid extraction process to extract TP and TF from linden flowers.
\end{abstract}

KEYWORDS

Extraction conditions, phenolic compounds, antioxidant activity, mathematical models.

\section{Introduction}

Plants, their extracts or pure components isolated from them are used in various industries, such as pharmaceutical, cosmetic, food, etc. During the last few decades, consumption of the plants and its products have been constantly growing. Studies showed that several classes of compounds present in these plants are responsible for biological activity. Among these compounds are phenolic compounds that represent a class of compounds tested for years, even decades, due to their multiple positive and useful effects in the human body, primarily as fighters against various diseases. It was shown that these compounds show a wide range of activities, such as antioxidant, antimicrobial, antiviral, antiallergic, anti-inflammatory, cytotoxic, as well as many other activities. $^{1}$

The genus Tilia L. from the Malvaceae family (native to Europe, Asia and North America), consists of about 44 species and two hybrids. ${ }^{2}$ Tilia cordata, Miller (Malvaceae), also known as linden, is a tall deciduous tree reaching up to $25 \mathrm{~m}$. Linden is cultivated in Europe and North America. The commercial products are obtained mainly from T. cordata and Tilia platyphyllos Scopoli, (Malvaceae). The yellowish-white flowers of T. cordata are arranged in clusters of 3-15 on a stalked erect cyme, and half joined to a membranous bract occurring in the leaf axils. The flowers are used, externally and internally, as a medicinal plant for the treatment of different ailments. ${ }^{3-4}$ The use of the flowers of $T$. cordata for therapeutic purposes dates back to the Middle Ages, and many pharmacological activities, such as antitussive, diaphoretic, diuretic, sedative, spasmolytic,

* To whom correspondence should be addressed.

E-mail: sonjajankovic1991@gmail.com hypotensive, as well as emolient and mild astringent activities, have been reported. ${ }^{5}$ The flowers of T. cordata are rich in carbohydrates, amino acids, and different secondary metabolites: phenolic acids (caffeic acid, $p$-coumaric, and chlorogenic acids), amino acids, polysaccharides, flavonoids (kaempferol, quercetin, myricetin and their glycosides, such as rutin, hyperoside, quercitrin, and isoquercitrin), volatile oils, and tannins. ${ }^{5-6}$

Presence of quercetin, kaempferol and their derivatives and phenolic acids in Tilia spp. were confirmed in previous studies. In 2014, Akyuz et al. ${ }^{7}$ analyzed phenolic compounds of the various blossom, leaf, and trunk extracts of T. rubra subsp. caucasica growing in Turkey by HPLC-UV and HPLC-UVMS. They reported high amounts of total phenolics $(17.548 \pm 0.04 \mathrm{mg}$ of gallic acid per $\mathrm{g}$ of dried sample) and total flavonoids (0.066 \pm $0.19 \mathrm{mg}$ of quercetin per $\mathrm{g}$ of dried sample), with the presence of some phenolic compounds, such as rutin, quercetin, catechin, caffeic acid, ferulic acid, chlorogenic acid, p-hydroxybenzoic acid, gallic acid and protocatechuic acid in T. rubra subsp. caucasica leaf. ${ }^{8}$ Myricetin, quercetin and kaempferol have been detected in T. platyphyllos. ${ }^{9}$ Quercetin has also been detected by HPLC in T. rubra and T. argentea leaves.

Extraction is a very important stage in the isolation, as well as the identification, of phenolic compounds. Solid-liquid extraction, also called leaching, has been widely used for recovering bioactive compounds from different parts of many plants using a suitable solvent. This process is based on diffusion of extractable bioactive compounds through the plant particles, followed by their dissolution in the bulk of the extracting solvent. However, the compositions of natural sources of 
phenolic compounds and the structure and physicochemical properties make a universal extraction protocol not conceivable. A definite extraction procedure must be designed and optimized for each phenolic source. ${ }^{10-11}$

The two most used optimization studies are single factor experiments and response surface methodology (RMS). In this study single factor experiments were used, despite being time-consuming and having several drawbacks, such as lack of information on the factors' interaction. ${ }^{7}$ However, fundamental information on the ranges for extraction parameters (factors) that showed significant effects $(\mathrm{P}<0.05)$ on the extraction of phenolic compounds from Tilia cordata M. flowers was obtained.

To optimize the extraction conditions, experimental data are often used for mathematical modelling. Mathematical modelling of solid-liquid extraction processes is an important engineering tool in the design process to reduce energy, time, and chemical reagents consumption. Kinetic modelling is of great importance for understanding complex diffusion, mass transfer and thermodynamic parameters affecting the extraction.

This study aimed to investigate the effect of ethanol concentration, liquid-solid ratio, time and temperature on the extraction of total phenols and total flavonoids from Tilia cordata M. flowers. Furthermore, we fitted three different kinetic models on the extraction data to verify the best description of the process's kinetic behaviour. Finally, thermodynamic parameters (entropy, enthalpy, and Gibb free energy) were determined.

\section{Experimental}

\subsection{Plant Materials}

The plant materials were harvested by hand in the morning, during the period of full blooming in three locations in southeastern Serbia. The herb materials were dried immediately after harvesting in a shady and well-aired place for 15 days. The dry plant materials were then packed in paper bags and kept in a dark, dry and cool place. Before being used, the plant material was comminuted by a hammer mill and sieved through a $6 \mathrm{~mm}$ screen.

\subsection{Chemicals and Reagents}

Folin-Ciocalteu reagent, aluminium chloride, gallic acid, 2,2-diphenyl-1-picrylhydrazyl (DPPH), 2,2'-azino-bis (3-ethylbenzothiazoline-6-sulfonic acid (ABTS), potassium-persulfate and catechin were purchased from the Sigma Chemical Corporation, St. Louis, MO, USA. All HPLC analysis standards were of analytical grade and were purchased from Sigma Chemical Corporation, St. Louis, USA) and Alfa Aesar (Karlsruhe, Germany). Acetonitrile, ethanol, methanol, and formic acid were purchased from Aldrich Chemical Co., Steinheim, Germany.

\subsection{Initial Contents of Phenols and Flavonoids in Linden Flowers $\left(q_{0}\right)$}

Dried linden flowers ( $1 \mathrm{~g}$ ) was transferred into a $250 \mathrm{~mL}$ Erlenmeyer flask with a ground stopper and covered with $100 \mathrm{~mL}$ of the freshly prepared extraction solvent. The extraction was carried out by the maceration method for $120 \mathrm{~min} .{ }^{12}$ The extract was separated from the residues by filtering through the Whatman No. 1 filter paper. The residues were extracted twice with the same freshly prepared extraction solvent and the extracts were combined. The combined extracts were concentrated and freed of solvent under reduced pressure at $45^{\circ} \mathrm{C}$, using a rotary evaporator (BUCHI Rotavapor R-200). The crude concentrated extracts were stored and diluted before use. The contents of total phenols (TP) and total flavonoids (TF) were determined spectrophotometrically (Shimadzu Spectrophotometer UV-1800, Japan). The extracts from dried plant material were prepared thrice, and the results averaged.

\subsection{Determination of Total Phenols in Extracts}

Total phenols (TP) were analyzed using the Folin-Ciocalteu method. ${ }^{13}$ The reaction mixture was prepared by mixing the diluted plant extract $(0.5 \mathrm{~mL}), 7.5 \mathrm{~mL}$ distilled water, $0.5 \mathrm{~mL}$ Folin-Ciocalteu reagent and $1.5 \mathrm{~mL} 20 \% \mathrm{Na}_{2} \mathrm{CO}_{3}$. After $2 \mathrm{~h}$ at room temperature, the absorbance was measured at $760 \mathrm{~nm}$ using a Shimadzu Spectrophotometer UV-1800 (Japan). The procedure was repeated twice for each extract. Based on the absorbance of standard solutions of gallic acid, concentrations of polyphenolic compounds $\left(\mu \mathrm{g} \mathrm{mL}^{-1}\right)$ were determined using the equation $A=0.0835[\mathrm{GA}]+0.0064(\mathrm{n}=7($ where $n=$ number of experimental repetition), $\left.\mathrm{r}^{2}=0.9996\right)$, where [GA] is the concentration of gallic acid. The extract's TP are expressed in $\mathrm{mg}$ of gallic acid equivalent (GAE) in a gram of dry weight (d.w.) \pm standard deviation (S.D.) ( $\mathrm{mg} \mathrm{GAE}^{-1}$ d.w. \pm S.D.).

\subsection{Determination of Total Flavonoids in Extracts}

The method is based on the fact that flavonoids form complexes with metal cations (such as $\mathrm{Al}^{3+}$ ). The reaction mixture was prepared using the following ingredients $-0.25 \mathrm{~mL}$ of diluted plant extract, $4 \mathrm{~mL}$ of deionized water and $0.3 \mathrm{~mL} 5 \%$ $\mathrm{NaNO}_{2}$. After $5 \mathrm{~min}, 1.5 \mathrm{~mL} 2 \% \mathrm{AlCl}_{3}$ was added, followed

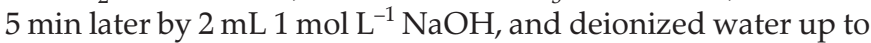
$10 \mathrm{~mL}$. Absorbances were measured at $415 \mathrm{~nm}$ against deionized water (blank) using a Shimadzu Spectrophotometer UV-1800 (Japan). ${ }^{14}$ Based on absorbances of the standard catechin solution, concentrations of flavonoids $\left(\mu \mathrm{g} \mathrm{mL}^{-1}\right)$ were obtained using the equation $\mathrm{A}=0.0252[\mathrm{C}]+0.006\left(\mathrm{n}=7, \mathrm{r}^{2}=0.9995\right)$, where [C] is the concentration of catechin. TF in the extract are shown as $\mathrm{mg}$ of catechin equivalent (CE) in a gram of dry weight (d.w.) \pm standard deviation (S.D.) ( $\mathrm{mg} \mathrm{CE} \mathrm{g}^{-1}$ d.w. \pm S.D.).

\subsection{Determination of the Antioxidant Activity of the Extracts}

The activity of extracts to scavenge a cation radical, namely 2,2'-azinobis-(3-ethylbenzothiaziline-6-sulfonate $\left(\mathrm{ABTS}^{\bullet+}\right.$ ) was carried out according to the method of Gong et al..$^{15}$ The scavenging effects of the extracts on a free radical, namely 2,2-diphenyl-1-picrilhydrazyl ( $\left.\mathrm{DPPH}^{\circ}\right)$ were monitored according to the method of Alothman et al. ${ }^{16}$

\subsection{HPLC Analysis of the Extracts}

Quantification of individual phenolic compounds was determined using reversed-phase HPLC method. An Agilent-1200 series HPLC with UV-Vis DAD for multi-wavelength detection was used. The column was thermostated at $30^{\circ} \mathrm{C}$. After injecting $5 \mu \mathrm{L}$ of the diluted plant extract, the separation was performed in an Agilent-Eclipse XDB C- $184.6 \times 150 \mathrm{~mm}$ column. Two solvents were used for the gradient elution: $\mathrm{A}\left(\mathrm{H}_{2} \mathrm{O}+2 \% \mathrm{HCOOH}\right)$ and $\mathrm{B}\left(80 \%\right.$ acetonitrile $\left.(\mathrm{ACN})+5 \% \mathrm{HCOOH}+\mathrm{H}_{2} \mathrm{O}\right)$. The elution programme used was as follows: from 0 to $10 \mathrm{~min} 0 \% \mathrm{~B}$, from 10 to 28 min gradually increases $0-25 \%$ B, from 28 to $30 \min 25 \% \mathrm{~B}$, from 30 to 35 min gradually increases $25-50 \%$ B, from 35 to 40 min gradually increases $50-80 \% \mathrm{~B}$, and finally for the last 5 min gradually decreases $80-0 \% \mathrm{~B}$. Flow rate of the mobile phase was $0.8 \mathrm{~mL} \mathrm{~min}^{-1}{ }^{17}$

Phenolic components present in the extracts were identified by comparing their retention times and spectra with pure components. The following standards were used: chlorogenic acid, $p$-coumaric acid, myricetin, rutin, quercetin, isoquercetin, 
and kaempferol. Quantitative determination of components was performed using an external standard. For each standard, stock solutions $\left(1 \mathrm{mg} \mathrm{mL}^{-1}\right)$ were prepared in $10 \%$ methanol. A calibration graph was constructed for each standard. Concentrations of components in extracts were calculated from obtained calibration graph. All analyses were performed in triplicate.

\subsection{The Contents of Phenols and Flavonoids in Saturated Liquid Extracts $\left(c_{\max }\right)$}

Macerated dried linden flowers $(1 \mathrm{~g})$ were transferred into a $250 \mathrm{~mL}$ Erlenmeyer flask with a ground stopper and covered with $100 \mathrm{~mL}$ of the extraction solvent. The extraction was carried out by the maceration method for $120 \mathrm{~min}$. The liquid extract was separated as before and used for extracting the phenolic compounds from a further portion $(1 \mathrm{~g})$ of the fresh plant material. The extraction was repeated with the liquid extract and an additional quantity of fresh plant material $(1 \mathrm{~g})$. The extraction solvent was evaporated under rotary evaporator at $45^{\circ} \mathrm{C}$. The crude concentrated extract was dissolved using extraction solvent until used for analyses. The contents of total phenols and flavonoids were determined spectrophotometrically using a Shimadzu Spectrophotometer UV-1800, (Japan).

\subsection{Optimization of the Extraction Procedure using Single-factor Experiments}

\subsubsection{Extraction Solvent Concentration}

The extraction solvent concentration was investigated using ethanol with concentration ranging from $0 \%$ to $100 \%$ (v/v). Each extraction was done at fixed condition of room temperature $\left(\approx 25^{\circ} \mathrm{C}\right)$ and $120 \mathrm{~min}$. The best extraction solvent was chosen based on the highest value of TP and TF.

\subsubsection{Extraction Solvent/Raw Material Ratio}

The impact of extraction solvent/solid ratio on the TP and TF was varied from 30, 40, 50 and $60 \mathrm{~mL} \mathrm{~g}^{-1}$. Extraction was accomplished by applying the best extraction solvent concentration, at room temperature and a fixed time of $120 \mathrm{~min}$. The extraction procedures were repeated as described. The best extraction solvent/solid ratio was chosen according to the highest values of TP and TF.

\subsubsection{Extraction Time}

The impact of extraction time on the TP and TF varied from 40, $80,120,160$ and $240 \mathrm{~min}$. Extraction was accomplished by applying the best extraction solvent concentration and the best extraction solvent/solid ratio at room temperature. The extraction procedures were repeated as described. The best extraction time was chosen according to the highest values of TP and TF.

\subsubsection{Extraction Temperature}

Lastly, the extraction was executed using the best extraction solvent concentration, extraction solvent/solid ratio and extraction time, under various temperatures, $25,35,45,55$ and $65^{\circ} \mathrm{C}$. The extraction procedure was repeated. The best extraction temperature was chosen according to the highest values of TP and TF.

\subsection{The Kinetics of Extraction}

The linden flowers $(1 \mathrm{~g})$ and the extracting solvent $(60 \mathrm{~mL})$ were put into a series of Erlenmeyer flasks $(250 \mathrm{~mL})$, and the flasks were macerated for $5,10,20,40,60,80$, and $120 \mathrm{~min}$. The temperature was controlled and maintained at $25 \pm 0.1^{\circ} \mathrm{C}$. After each time interval, a flask was taken out of the thermostatic bath, and the liquid extract was separated from the plant residues by vacuum filtration. The content of TP and TF in the liquid extracts was determined spectrophotometrically. The procedure was repeated at $35 \pm 0.1^{\circ} \mathrm{C}$ and $45 \pm 0.1^{\circ} \mathrm{C}$.

Three different mathematical models for describing the TP and TF extraction kinetics were considered in this study. Their performance in adjusting the data for phenolic compounds extraction from linden flowers using $50 \%$ ethanol was compared. The three models and their respective parameters are shown in Table 1.

\subsection{Validity Kinetic Models}

The applicability of a kinetic model can be identified using the coefficient of determination $\left(\mathrm{R}^{2}\right)$, root mean square (RMS), ${ }^{18}$ and standard deviation (S.D.), ${ }^{19-20}$ as shown in Equations 1 and 2.

$$
\begin{aligned}
& \text { RMS }=\sqrt{\frac{1}{N} \sum_{i=1}^{N}\left(\frac{\overline{\mathrm{q}}_{\exp }-\overline{\mathrm{q}}_{\text {cal }}}{\overline{\mathrm{q}}_{\exp }}\right)} \\
& \text { S.D. }=\sqrt{\frac{1}{\mathrm{~N}-1} \sum_{\mathrm{i}=1}^{\mathrm{N}}\left(\left|\frac{\overline{\mathrm{q}}_{\exp (\mathrm{i})}-\overline{\mathrm{q}}_{\mathrm{cal}(\mathrm{i})}}{\overline{\mathrm{q}}_{\exp (\mathrm{i})}}\right|-\mathrm{AARE}\right)^{2}}
\end{aligned}
$$

Absolute average relative error (AARE) was calculated by using Equation 3,

$$
\operatorname{AARE}=\frac{1}{\mathrm{~N}} \cdot \sum_{\mathrm{i}-1}^{\mathrm{N}}\left(\left|\frac{\overline{\mathrm{q}}_{\exp (\mathrm{i})}-\overline{\mathrm{q}}_{\mathrm{cal}(\mathrm{i})}}{\overline{\mathrm{q}}_{\exp (\mathrm{i})}}\right|\right)
$$

The higher the value of $\mathrm{R}^{2}$ and the lower the RMS and S.D., the better the fit. $^{18}$

\subsection{Thermodynamic Study}

Activation energy $\left(E_{a}\right)$ can be determined by experimental measurement of the slow extraction coefficient (model based on unsteady diffusion through plant material) at various temperatures by using the Arrhenius equation, as shown in Equation 4 :

$$
\mathrm{k}=\mathrm{A} \cdot \mathrm{e}^{-\mathrm{E}_{\mathrm{a}} / \mathrm{RT}}
$$

Equation 4 can be converted to the linear expression given in Equation 5.

$$
\ln \mathrm{k}=\ln \mathrm{A} \cdot \mathrm{e} \frac{\mathrm{Ea}_{\mathrm{a}}}{\mathrm{R}} \cdot \frac{1}{\mathrm{~T}}
$$

Here $\mathrm{k}, \mathrm{A}, \mathrm{E}_{\mathrm{a}}, \mathrm{R}$, and $\mathrm{T}$ refer to the rate constant $\left(\mathrm{min}^{-1}\right)$, pre-exponential factor, activation energy $\left(\mathrm{kJ} \mathrm{mol}^{-1}\right)$, gas constant $\left(8.314 \mathrm{~J} \mathrm{~mol}^{-1} \mathrm{~K}^{-1}\right)$, and absolute temperature $(\mathrm{K})$, respectively. $\mathrm{E}_{\mathrm{a}}$ and A can be obtained using the slope and y-intercept of the plot of lnk versus 1/T, based on Equation 5 .

Thermodynamic parameters $\left(\Delta \mathrm{G}^{\mathrm{o}}, \Delta \mathrm{H}^{\mathrm{o}}, \Delta \mathrm{S}^{\circ}\right)$ were calculated from the van't Hoff equation:

$$
\Delta \mathrm{G}^{\mathrm{o}}=-\mathrm{RT} \ln \mathrm{K}
$$

Here $\Delta \mathrm{G}^{\mathrm{o}}$ is the standard Gibbs free energy change $\left(\mathrm{kJ} \mathrm{mol}^{-1}\right)$ and is the equilibrium constant, which is defined as follows:

$$
\begin{gathered}
K=\frac{\mathrm{q}_{\mathrm{ex}}}{\mathrm{q}_{\mathrm{R}}}=\frac{\mathrm{q}_{\mathrm{ex}}}{\mathrm{q}_{\mathrm{o}}-\mathrm{q}_{\mathrm{ex}}} \\
\Delta \mathrm{G}^{\mathrm{o}}=\Delta \mathrm{H}^{\mathrm{o}}-\mathrm{T} \Delta \mathrm{S}^{\mathrm{o}}
\end{gathered}
$$

where $\mathrm{q}_{\mathrm{ex}}$ is the TP content or TF content in the extracts, $\mathrm{q}_{\mathrm{R}}$ is the TP content or TF content that remained in the residual plant material in contact with the extract, and $\mathrm{q}_{\mathrm{o}}$ is the TP content or TF content in the original plant material. All three values of the dry plant material are in the $\mathrm{mg} \mathrm{kg}^{-1}$. Values $\mathrm{q}_{\mathrm{o}}$ and $\mathrm{q}_{\mathrm{ex}}$ were determined experimentally, while values $\mathrm{q}_{\mathrm{R}}$ were calculated 
Table 1 Kinetics equations of solid-liquid extraction and their linearized forms.

\begin{tabular}{lll}
\hline Model & Kinetic equation & Linear transformation \\
\hline Unsteady diffusion through plant material & $\frac{\mathrm{q}}{\mathrm{q}_{\mathrm{o}}}=(1-\mathrm{b}) \cdot \mathrm{e}^{-\mathrm{kt}}$ & $\ln \frac{\mathrm{q}}{\mathrm{q}_{\mathrm{o}}}=\ln (1-\mathrm{b})-\mathrm{kt}$ \\
Film theory & $\frac{\mathrm{c}}{\mathrm{c}_{\mathrm{S}}}=1-\left(1-\mathrm{b}^{\prime}\right) \mathrm{e}^{-\mathrm{k}^{\prime} \mathrm{t}}$ & $\ln \left(1-\frac{\mathrm{c}}{\mathrm{c}_{\mathrm{S}}}\right)=1-\left(1-\mathrm{b}^{\prime}\right)-\mathrm{k}^{\prime} \mathrm{t}$ \\
Empirical equation of Ponomaryov & & $\underline{\mathrm{q}_{\mathrm{o}}-\mathrm{q}}$ \\
\end{tabular}

Notation: $b, b^{\prime}$ and $b^{\prime \prime}$ - washing coefficient according to the unsteady diffusion model, the film model, and the empirical model Ponomaryov, respectively; $c$ - concentration of extractive substances in liquid extract during the extraction, $\mathrm{mg} \mathrm{g}^{-1} \mathrm{dm} ; \mathrm{c}_{\mathrm{S}}-$ maximum concentration of extractive substances in a 9 solvent at a temperature, $\mathrm{mg} \mathrm{g}^{-1}$

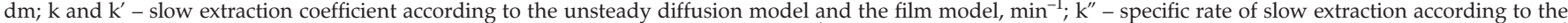
empirical model Ponomaryov, i.e. the slope of the dependence $\left(1-\mathrm{q} / \mathrm{q}_{\mathrm{o}}\right)$ versus time, $\mathrm{min}^{-1}$; $\mathrm{q}$-content of extractive substances in plant material during the extraction, $\mathrm{mg}^{-1}$ $\mathrm{dm} ; \mathrm{q}_{\mathrm{o}}$ - content of extractive substances present in plant material, $\mathrm{mg} \mathrm{g}^{-1} \mathrm{dm}$; and - time, min.

using the mass balance equation $\left(\mathrm{q}_{\mathrm{R}}=\mathrm{q}_{\mathrm{o}}-\mathrm{q}_{\mathrm{ex}}\right)$. Equation 9 is obtained by using Equation 6 and Equation 8.

$$
\ln K=-\frac{\Delta \mathrm{G}^{*}}{\mathrm{RT}}=-\frac{\Delta \mathrm{H}^{\mathrm{o}}}{\mathrm{RT}}+\frac{\Delta \mathrm{S}^{\mathrm{o}}}{\mathrm{R}}
$$

The standard enthalpy change, $\Delta \mathrm{H}^{\mathrm{o}}\left(\mathrm{kJ} \mathrm{mol}^{-1}\right)$ and standard entropy change, $\Delta \mathrm{S}^{\mathrm{o}}\left(\mathrm{J} \mathrm{mol}^{-1} \mathrm{~K}^{-1}\right)$ can be obtained by using the slope and y-intercept of the plot of $\operatorname{lnK}$ versus $1 \mathrm{~T}^{-1}$, based on Equation 9.

\subsection{Temperature Extraction Coefficient}

The temperature extraction coefficient, which indicates increasing the extraction of phenolic compounds from linden flowers for every $10{ }^{\circ} \mathrm{C}$ increase in extraction temperature, is defined as follows: ${ }^{18}$

$$
\mathrm{y}_{\mathrm{T}}=\mathrm{y}_{\mathrm{T}_{0}} \cdot \gamma^{\mathrm{T} / 10}
$$

where $\gamma$ is the temperature extraction coefficient, and $\mathrm{y}_{\mathrm{r}}$ and $\mathrm{y}_{\mathrm{t}_{0}}$ are the TP or TF yields at temperature $\mathrm{T}$ and $\mathrm{T}_{\mathrm{o}}$ (in ${ }^{\circ} \mathrm{C}$ ), respectively. The temperature extraction coefficient was calculated from the linearized transformation of Equation 10, i.e.

$$
\ln \mathrm{y}_{\mathrm{T}}=\ln \mathrm{y}_{\mathrm{T}_{0}}+\frac{\mathrm{T}}{10} \ln \gamma
$$

\section{Results and Discussion}

\subsection{Effect of Extraction Solvent Concentration}

The phenolic yield is affected by the solubility of phenolic compounds and the solvent's polarity. ${ }^{22-23}$ Ethanol, methanol and acetone at different concentrations with distilled water have commonly been used as solvents for the extraction of polyphenols. ${ }^{12,16,24}$ In this study different ethanol fractions with distilled water $(0 \%, 30 \%, 50 \%, 70 \%, 100 \%)$ were used. As shown in Fig. 1, $30 \%$ and $50 \%$ ethanol samples recorded higher phenolic yields than $70 \%$ and $100 \%$ ethanol samples. The high solubility of oxygen can explain this in $80 \%$ and $100 \%$ ethanol samples, which play an important role in facilitating degradation reactions of polyphenols (reactive oxygen species (ROS) are potential oxidizing agents for polyphenols). ${ }^{25-26}$ Also, the extraction efficiency of the phenolic compounds is reduced by using pure ethanol as the solvent since the phenols, due to a number of hydroxyl groups (such as flavonoids, especially those with sugars in the molecule), are hydrophilic, and as such generally more soluble in water-ethanol solutions than pure alcohol. ${ }^{27}$ Binary-solvent system demonstrated a higher yield to TP and TF. Compared to the mono-solvent system (water or ethanol) in the present study, previous studies also reported this finding. The influence of the solvent extraction (50-80\% of ethanol) and

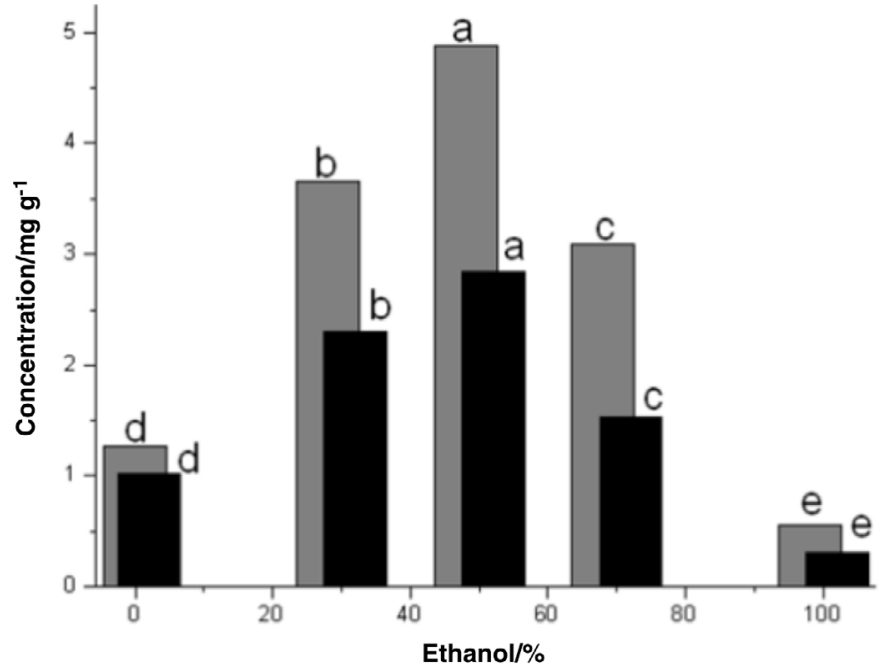

Figure 1 Effect of extraction solvent concentration on the extraction contents of polyphenols (grey) and flavonoids (black) from linden flowers (time $-120 \mathrm{~min}$, liquid-solid ratio-20 $\mathrm{V} / \mathrm{m}$, temperature $-25{ }^{\circ} \mathrm{C}$ ). The values of contents of polyphenols or flavonoids marked with the different lower-case letters $(\mathrm{a}-\mathrm{e})$ are significantly $(\mathrm{P}<0.05)$ different between the different extracts.

temperature $\left(25-80{ }^{\circ} \mathrm{C}\right)$ on the extractability of TP from milled soybeans has been published previously. ${ }^{28}$ The authors reported that $50 \%$ ethanol was the most effective solvent, which is similar to the results obtained in this study. Rostango et al. ${ }^{29}$ found that it is necessary to add a certain amount of water in the extraction solvent to improve the extraction of phenolic compounds.

In this study, $50 \%$ ethanol was selected as the best extraction solvent to optimize the subsequent extraction parameters.

\subsection{Effect of Liquid-Solid Ratio}

The impact of the liquid-solid ratio on the extraction of TP and TF from linden flowers was tested using four ratios $(30,40,50$, $60 \mathrm{~mL} \mathrm{~g}^{-1}$ ) over a 120 min extraction period with $50 \%$ ethanol at $25^{\circ} \mathrm{C}$. The amount of TP and TF extracted per g dry weight (d.w.) is presented in Fig. 2. The increase of TP and TF content with the increase of the liquid-solid ratio is consistent with mass transfer principles. During mass transfer within the solid, the driving force is considered to be the concentration gradient, which was greater when a higher liquid-solid ratio was used, increasing the diffusion rate. ${ }^{30}$

\subsection{Effect of Extraction Time}

Extraction time is crucial in solvent extraction of phenolic compounds as an appropriate extraction time can result in time and 


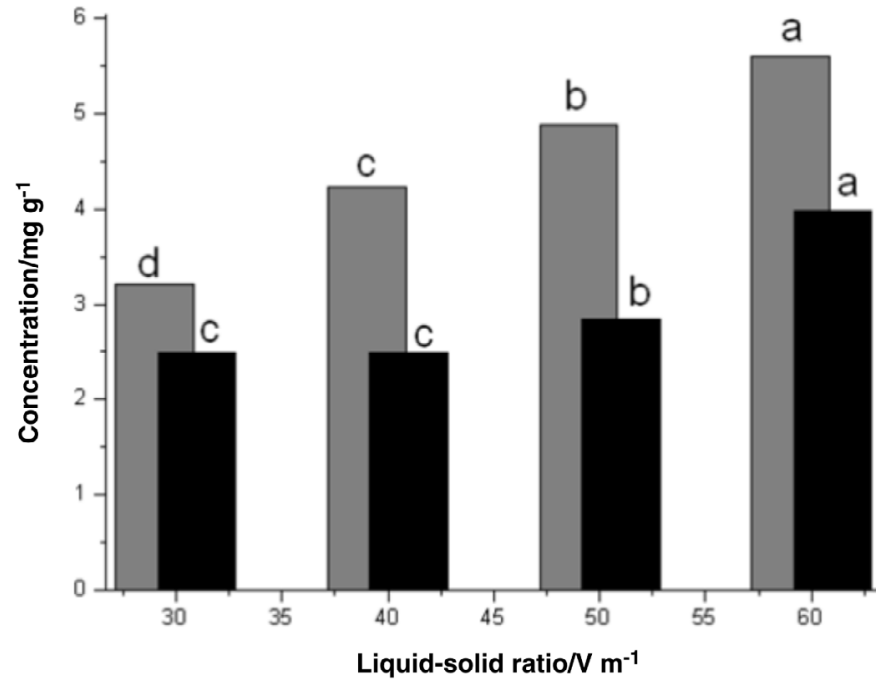

Figure 2 Effect of liquid-solid ratio on the extraction contents of phenols (grey) and flavonoids (black) from linden flowers (time - $120 \mathrm{~min}, 50 \%$ ethanol, temperature $\left.-25^{\circ} \mathrm{C}\right)$. The values marked with the different lower-case letters $(\mathrm{a}-\mathrm{d})$ are significantly $(\mathrm{P}<0.05)$ different.

cost-saving. The effects of extraction time on the phenolic contents (TP and TF) of the extract are shown in Fig. 3. Overall, extraction time had a significant $(\mathrm{P}<0.05)$ effect on the contents of TP and TF.

In general, the maximum concentration of phenolic compounds was achieved at an extraction time of $120 \mathrm{~min}$. After this point, the TP and TP decreased. It was believed that prolonged extraction time would lead to more oxygen exposure and thus increase the chances of oxidation on phenolic compounds. ${ }^{31-32}$ On the other hand, the phenolic contents were observed to have no significant change $(\mathrm{P}<0.05)$ after 160 min extraction time. The phenomenon could be explained by Fick's second law of diffusion, revealing that final equilibrium will be attained between the solution concentrations in the solid matrix and solvent after a particular duration. ${ }^{33}$

\subsection{Effect of Extraction Temperature}

The effect of extraction temperature was studied with $50 \%$ ethanol and liquid-solid ratio $60\left(\mathrm{~mL} \mathrm{~g}^{-1}\right)$ over $120 \mathrm{~min}$ as extrac-

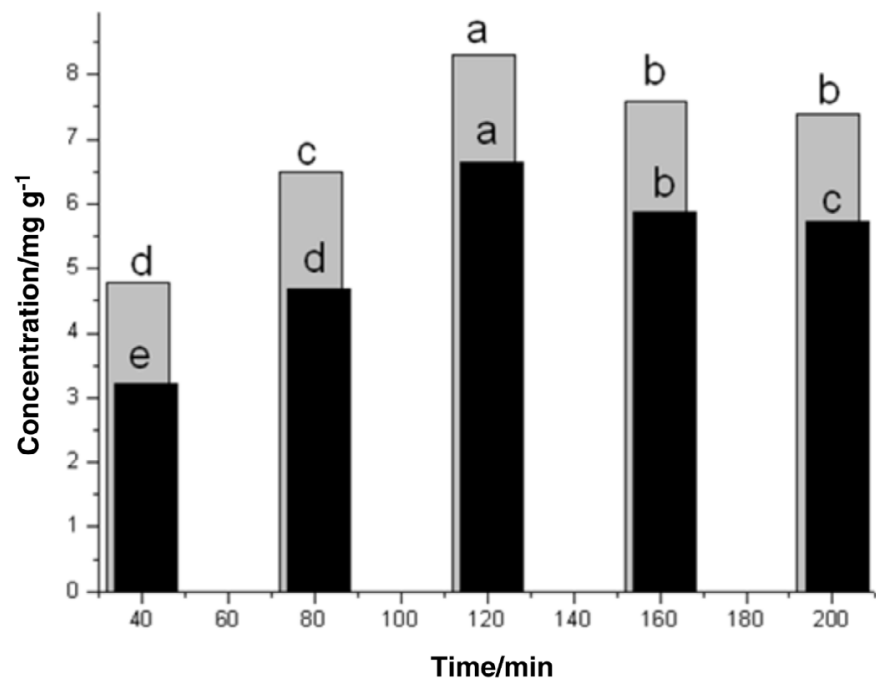

Figure 3 Effect of extraction time on the extraction contents of phenols (grey) and flavonoids (black) from linden flowers (liquid-solid ratio $60 \mathrm{~V} / \mathrm{m}, 50 \%$ ethanol, temperature $\left.-25^{\circ} \mathrm{C}\right)$. The values marked with the different lower-case letters $(\mathrm{a}-\mathrm{e})$ are significantly $(\mathrm{P}<0.05)$ different. tion conditions. The impact of extraction temperature on the $\mathrm{TP}$ and TF were investigated in the range from 25 to $65^{\circ} \mathrm{C}$. As shown in Fig.4, extraction temperature demonstrated a significant $(\mathrm{P}<0.05)$ effect on both phenolic contents and flavonoid contents. The increment of TP and TF as a function of temperature was in agreement with previous studies that reported that the yield of phenolic compounds would increase with increasing extraction temperature. ${ }^{32,34}$ Heat could enhance the recovery of phenolic compounds from plant materials by increasing the diffusivity and the solubility of phenolic compounds in the extraction solvent. ${ }^{35-36}$ With the increase of extraction temperature from 25 to $45{ }^{\circ} \mathrm{C}$, TP and $\mathrm{TF}^{\prime}$ 's extraction yield quickly increased from 8.36 to $15.77 \mathrm{mg} \mathrm{GAE} \mathrm{g}^{-1}$ d.w. (88.6 \%) and from 6.65 to $12.05 \mathrm{mg} \mathrm{CE} \mathrm{g}^{-1} \mathrm{~d} . w .(81.2 \%)$, respectively. However, with the increase of extraction temperature from 45 to $65{ }^{\circ} \mathrm{C}$, the extraction yield showed a little increase from 15.77 to $17.82 \mathrm{mg}$ $\mathrm{GAE} \mathrm{g}^{-1}$ d.w. (13.0 \%) and 12.05 to $13.20 \mathrm{mg} \mathrm{CE} \mathrm{g}^{-1}$ d.w. $(9.5 \%)$, respectively.

\subsection{Composition of Linden Flowers Extract $\left(q_{0}\right)$}

Results for TP, TF, DPPH and ABTS for linden extract indicated that the extract possessed a high content of TP (17.011 mg $\left.\mathrm{GAE} \mathrm{g}^{-1}\right)$ and TF (12.562 $\left.\mathrm{mg} \mathrm{CE} \mathrm{g}^{-1}\right)$, and high antioxidant activity (ABTS: $1.62 \mathrm{mmol} \mathrm{TE} \mathrm{g}^{-1}$; DPPH: $1.05 \mathrm{mmol} \mathrm{TE} \mathrm{g}^{-1}$ ). HPLC-DAD analysis was performed, to establish the polyphenolic profile of obtained extract. Three phenolic acids were indentified and quantified in the ethanol extract of linden flower: chlorogenic acid $\left(0.214 \mathrm{mg} \mathrm{g}^{-1}\right)$, p-coumaric acid $\left(0.129 \mathrm{mg} \mathrm{g}^{-1}\right)$ and ferulic acid $\left(0.971 \mathrm{mg} \mathrm{g}^{-1}\right)$. Six flavonol were identified, myricetin-glycoside $\left(0.849 \mathrm{mg} \mathrm{g}^{-1}\right)$, rutin $\left(0.324 \mathrm{mg} \mathrm{g}^{-1}\right)$, hyperosid $\left(0.843 \mathrm{mg} \mathrm{g}^{-1}\right)$, isoquercetin $\left(0.052 \mathrm{mg} \mathrm{g}^{-1}\right)$, quercetin $\left(1.713 \mathrm{mg} \mathrm{g}^{-1}\right)$ and kaempferol $\left(0.118 \mathrm{mg} \mathrm{g}^{-1}\right)$. Results showed that dominant compounds in the linden extract were ferulic acid and quercetin.

\subsection{Kinetics of Total Polyphenols and Flavonoid}

\section{Extraction}

The change of TP and TF in the liquid extracts with the progress of extraction is presented in Fig. 5.

Curves are of the same shape as those of classical extraction from plant materials. Two periods of extraction can easily be observed in both TP and TF:

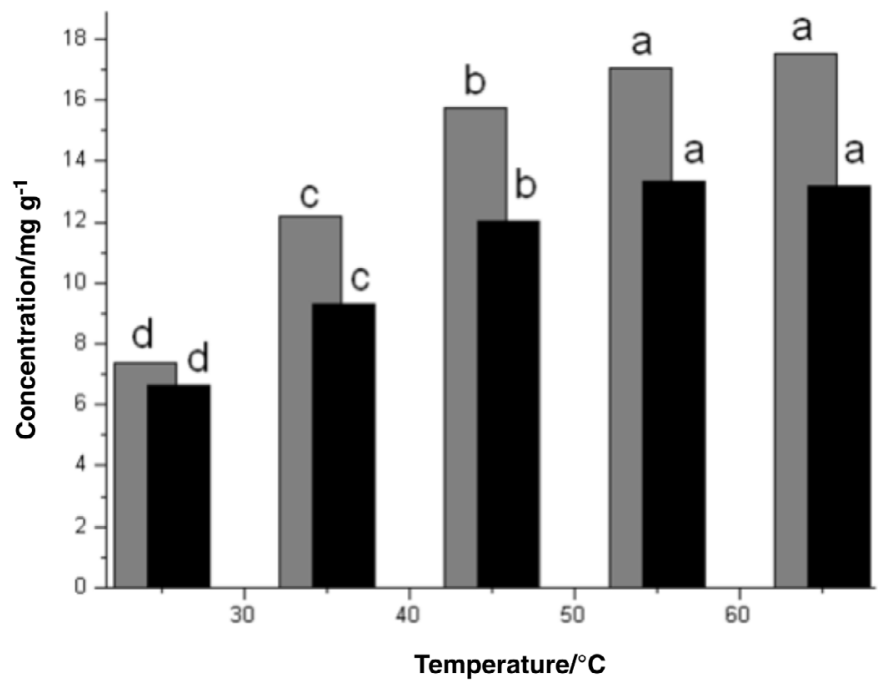

Figure 4 Effect of extraction temperature on the extraction contents of phenols (grey) and flavonoids (black) from linden flowers (liquid-solid ratio $-60 \mathrm{~mL} \mathrm{~g}^{-1}$, time $-120 \mathrm{~min}, 50 \%$ ethanol). The values marked with the different lower-case letters $(\mathrm{a}-\mathrm{d})$ are significantly $(\mathrm{P}<0.05)$ different. 

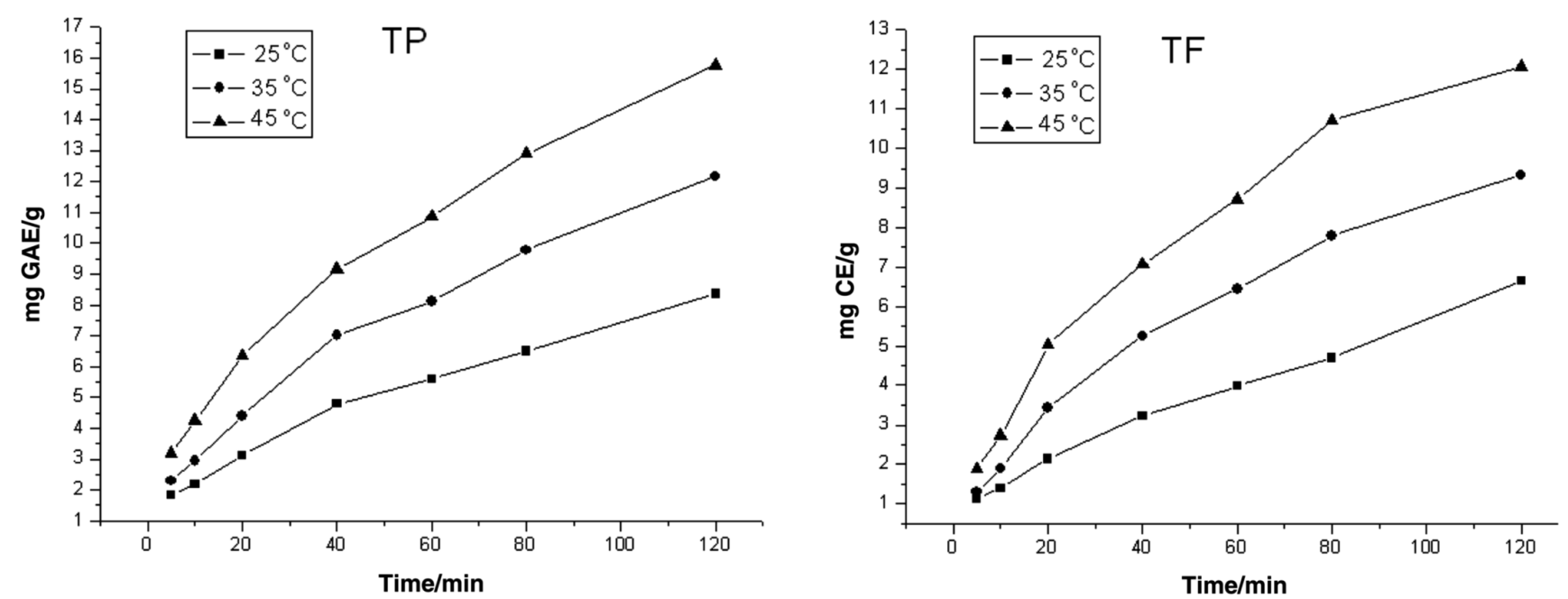

Figure 5 Variation of the TP and TF in the liquid extracts with increasing maceration time during extraction at $(\bullet) 25 \pm 0.1^{\circ} \mathrm{C}$; $(\boldsymbol{\square}) 35 \pm 0.1^{\circ} \mathrm{C}$ and (ム) $45 \pm 0.1^{\circ} \mathrm{C}\left(50 \%\right.$ ethanol; $60 \mathrm{~mL} \mathrm{~g}^{-1}$ liquid-solid ratio).

- Washing, characterized by a rapid increase in the concentration in the early beginning of the process (the rapid extraction process at the beginning was due to free phenolic compounds on the surface of the milled linden flowers that was exposed to fresh solvent), and

- slow extraction (after the first $40 \mathrm{~min}$ ), characterized by a slow increase in the concentration with the progress of extraction.

The knowledge on the mechanism and the kinetics of phenolic compounds extraction are generally needed for optimizing the operating conditions and designing the extraction process. ${ }^{37}$

Based on the two-step mechanism, we modelled the kinetics of the TP and TF from linden flowers by the Ponomaryov equation, film theory and the unsteady-state diffusion through the plant material, the kinetic equations and their linearized form are presented in Table 1.

Figure 6 illustrates the linearized form of the corresponding basic kinetic equations given in Table 2 . As can be seen, two equations fit the experimental data quite well in the second part of the extraction. The kinetic parameter for model based on the unsteady diffusion through plant material, model based on the film theory and empirical model of Ponomaryov were obtained by plotting $\log \mathrm{q} / \mathrm{q}_{\mathrm{o}}, \ln \left(1-\mathrm{c} / \mathrm{c}_{\mathrm{S}}\right)$, and $1-\mathrm{q} / \mathrm{q}_{\mathrm{o}}$, versus $\mathrm{t}$, respectively.

The equations are two-parametric, where one parameter $\left(b, b^{\prime}\right.$ and $\left.b^{\prime \prime}\right)$ represents the washing (so-called washing coefficient) and the second one $\left(k, k^{\prime}\right.$ and $\left.k^{\prime \prime}\right)$ represents the slow extraction (so-called slow extraction coefficient). Parameters of the kinetic

Table 2 Values of kinetics parameters for total polyphenols and flavonoids extraction.

\begin{tabular}{|c|c|c|c|c|c|}
\hline \multirow[t]{2}{*}{ Model } & \multirow[t]{2}{*}{$\begin{array}{c}\text { Temperature } \\
/ \mathrm{K}\end{array}$} & \multicolumn{2}{|c|}{$\begin{array}{l}\text { Washing } \\
\text { coefficient }\end{array}$} & \multicolumn{2}{|c|}{$\begin{array}{l}\text { Slow extraction } \\
\text { coefficient } / \mathrm{min}^{-1}\end{array}$} \\
\hline & & TP & $\mathrm{TF}$ & TP & $\mathrm{TF}$ \\
\hline $\begin{array}{l}\text { Unsteady-state } \\
\text { diffusion }\end{array}$ & $\begin{array}{l}298 \\
308 \\
318\end{array}$ & $\begin{array}{l}0.525 \\
0.658 \\
0.732\end{array}$ & $\begin{array}{l}0.437 \\
0.647 \\
0.729\end{array}$ & $\begin{array}{l}3.21 \cdot 10^{-3} \\
3.63 \cdot 10^{-3} \\
3.84 \cdot 10^{-3}\end{array}$ & $\begin{array}{l}4.07 \cdot 10^{-3} \\
4.25 \cdot 10^{-3} \\
4.55 \cdot 10^{-3}\end{array}$ \\
\hline Film theory & $\begin{array}{l}298 \\
308 \\
318\end{array}$ & $\begin{array}{l}0.092 \\
0.094 \\
0.105\end{array}$ & $\begin{array}{l}0.074 \\
0.076 \\
0.078\end{array}$ & $\begin{array}{r}4.36 \cdot 10^{-3} \\
8.12 \cdot 10^{-3} \\
13.27 \cdot 10^{-3}\end{array}$ & $\begin{array}{r}4.37 \cdot 10^{-3} \\
9.47 \cdot 10^{-3} \\
17.30 \cdot 10^{-3}\end{array}$ \\
\hline Ponomaryov & $\begin{array}{l}298 \\
308 \\
318\end{array}$ & $\begin{array}{l}0.172 \\
0.256 \\
0.349\end{array}$ & $\begin{array}{l}0.138 \\
0.236 \\
0.270\end{array}$ & $\begin{array}{l}2.64 \cdot 10^{-3} \\
3.83 \cdot 10^{-3} \\
4.89 \cdot 10^{-3}\end{array}$ & $\begin{array}{l}2.95 \cdot 10^{-3} \\
5.00 \cdot 10^{-3} \\
7.20 \cdot 10^{-3}\end{array}$ \\
\hline
\end{tabular}

models: the washing and the slow extraction coefficient were calculated from the experimental data by means of the linear regression method using the proper linearized form of the kinetics equations. Their values are presented in Table 2.

The model based on film theory predicts the smallest values of washing coefficient and the highest values of the slow extraction coefficient. For the three models, it was observed that, their kinetic parameters increased with increase in temperature, which amply explains the reason behind the increase in the TP and TF yield as temperature increase.

\subsection{Comparison of the Kinetic Models}

The criteria used to evaluate how well models represents the experimental data and to select the best one was the magnitudes of the linear coefficient of determination $\left(R^{2}\right)$, root mean square (RMS) and standard deviation (S.D.). Table 3 summarizes the $R^{2}$, RMS and S.D. percentage values for each model at different temperatures. Table 3 shows that the average RMS individual values were less than $\pm 8 \%$ for each of the three models considered. The same is true for the average S.D. individual values. Thus, based on their low RMS and S.D., each of the models examined reasonably described the kinetics of TP and TF extraction from linden flowers. These findings were in line with the results obtained by Kitanović et al. ${ }^{18}$ for the resinoid extraction from aerial parts of Hyperium perforatum L., and the results obtained by Menkiti et al. ${ }^{20}$ for the oil extraction from Terminalia catappa L.

Also, it was observed that the RMS decreased, and the linear correlation coefficient increased in the following order;

Film theory $\rightarrow$ Empirical equation of Ponomaryov $\rightarrow$ Unsteady diffusion through plant material.

Based on these results, the model based on the unsteady diffusion through plant material, having the lowest values of RMS and SD, and the highest values of the linear correlation coefficients, was selected as the best model for the TP and TF extraction kinetics from linden flowers.

\subsection{Thermodynamic Analysis}

The temperature extraction coefficient $(\gamma$ was calculated based on a linear regression of $\ln _{\mathrm{T}}$ and $\mathrm{T} / 10$ using Equation 11, the activation energy $\left(E_{a}\right)$ was calculated based on a linear regression of $\operatorname{lnK}$ and 1/T using Equation 6, the Gibbs free energy change $\left(\Delta G^{\circ}\right)$ was determined using Equation 7 , and the enthalpy change $\left(\Delta \mathrm{H}^{\circ}\right)$ and entropy change $\left(\Delta \mathrm{S}^{\circ}\right)$ were calculated based on a linear regression of $\ln K$ and $1 / \mathrm{T}$ using Equation 

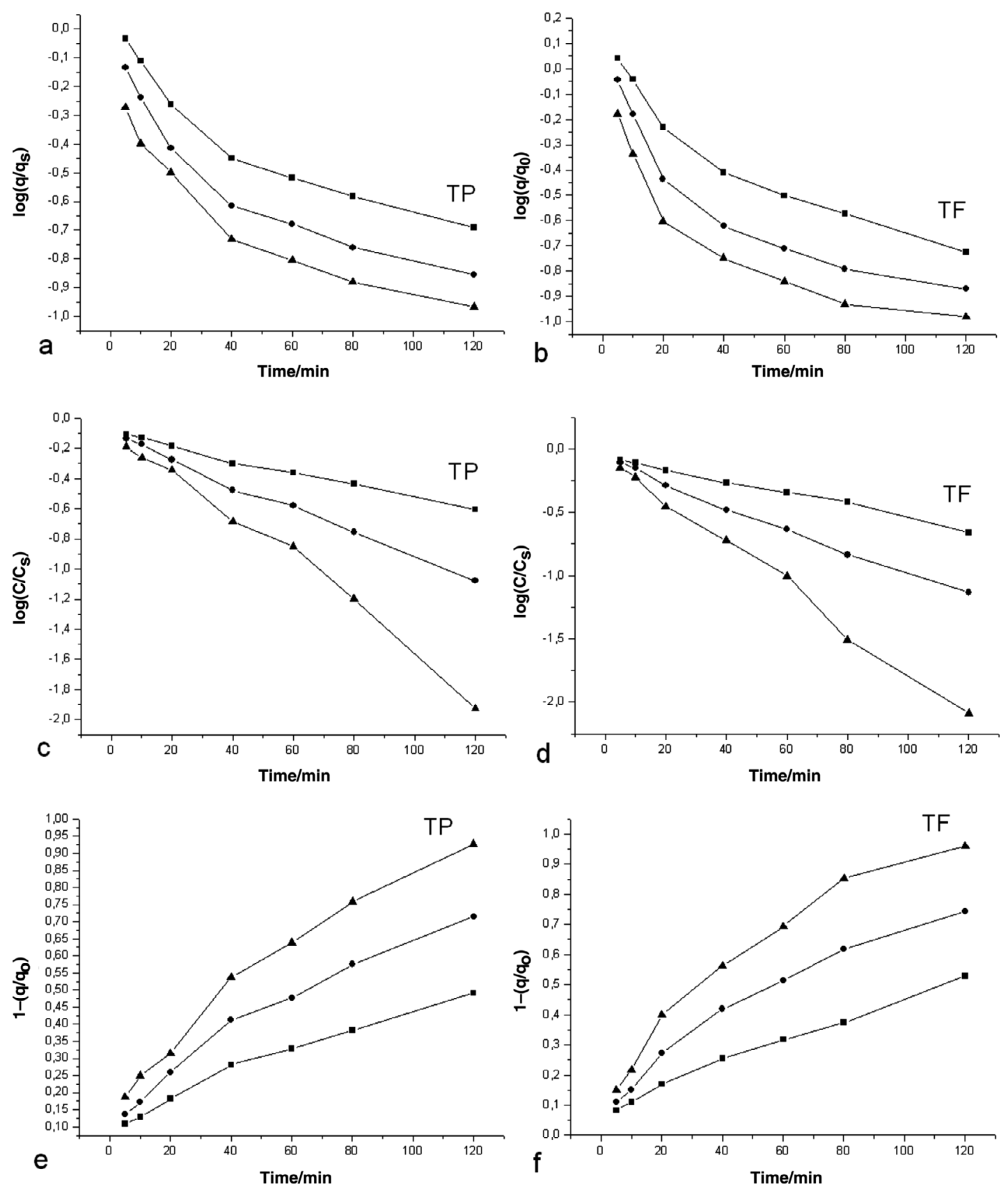

Figure 6 Linearized forms of kinetics equations: model based on unsteady diffusion through plant material (a) for TP and (b) TF extraction; model based on film theory (c) for TP and (d) TF extraction, and Ponomaryov's empirical equation (e) for TP and (f) TF extraction; at (ם) $25 \pm 0.1^{\circ} \mathrm{C} ;(\boldsymbol{\bullet}) 35 \pm$ $0.1^{\circ} \mathrm{C}$ and $(\mathbf{\Delta}) 45 \pm 0.1^{\circ} \mathrm{C}$ (50\% ethanol; $60 \mathrm{~mL} \mathrm{~g}^{-1}$ liquid-solid ratio).

10. The calculated values of $\gamma, \mathrm{E}_{\mathrm{a}}, \mathrm{K}, \Delta \mathrm{G}^{\mathrm{o}}, \Delta \mathrm{H}^{\mathrm{o}}$ and $\Delta \mathrm{S}^{\mathrm{o}}$ are shown in Table 4.

The TP and TF yields increased by a factor 1.37 and 1.51 for every $10^{\circ} \mathrm{C}$ rise in temperature. Values of the temperature coeffi- cient are higher compared to previously published ones for the hempseed oil extraction from hemp (Cannabis sativa L.) $(1.012-1.025)^{18}$ and the oil extraction from the olive cake $(1.02-1.14) .^{38}$

Table 3 Comparison of the percentage RMS, SD and $\mathrm{R}^{2}$ for different kinetic models.

\begin{tabular}{|c|c|c|c|c|c|c|c|c|c|c|}
\hline & \multirow[t]{2}{*}{ Kinetic model } & \multicolumn{3}{|c|}{$25^{\circ} \mathrm{C}$} & \multicolumn{3}{|c|}{$35^{\circ} \mathrm{C}$} & \multicolumn{3}{|c|}{$45^{\circ} \mathrm{C}$} \\
\hline & & $\%$ RMS & $\% \mathrm{SD}$ & $\% \mathrm{R}^{2}$ & $\%$ RMS & $\% \mathrm{SD}$ & $\% \mathrm{R}^{2}$ & $\%$ RMS & $\% \mathrm{SD}$ & $\% \mathrm{R}^{2}$ \\
\hline \multirow[t]{3}{*}{ TP } & Unsteady-state diffusion & 0.48 & 0.58 & 99.64 & 0.99 & 1.21 & 99.50 & 0.61 & 0.38 & 99.99 \\
\hline & Film theory & 6.23 & 6.56 & 98.23 & 5.52 & 6.03 & 98.85 & 5.05 & 5.59 & 99.15 \\
\hline & Ponomaryov & 0.86 & 0.96 & 99.95 & 2.32 & 2.79 & 98.60 & 1.56 & 1.98 & 99.99 \\
\hline \multirow[t]{3}{*}{ TF } & Unsteady-state diffusion & 1.09 & 1.33 & 99.49 & 0.30 & 0.37 & 99.97 & 0.18 & 0.18 & 99.99 \\
\hline & Film theory & 6.21 & 6.85 & 99.07 & 7.72 & 7.78 & 99.30 & 7.27 & 7.02 & 98.77 \\
\hline & Ponomaryov & 1.16 & 0.99 & 99.99 & 3.85 & 1.04 & 99.86 & 0.92 & 1.12 & 99.71 \\
\hline
\end{tabular}


Table 4 Thermodynamic parameters for the extraction process of TP and TF from linden flowers.

\begin{tabular}{lccccccc}
\hline & $\begin{array}{c}\text { Tempera- } \\
\text { ture } /{ }^{\circ} \mathrm{C}\end{array}$ & $\mathrm{E}_{\mathrm{a}}$ & $\begin{array}{c}\mathrm{K} \\
/ \mathrm{KJ} \mathrm{mol}^{-1}\end{array}$ & $\begin{array}{c}\Delta \mathrm{G}^{\circ} \\
/ \mathrm{K} \mathrm{mol}^{-1}\end{array}$ & $\begin{array}{c}\Delta \mathrm{H}^{\circ} \\
/ \mathrm{kJ} \mathrm{mol}^{-1}\end{array}$ & $\begin{array}{c}\Delta \mathrm{S}^{\circ} \\
/ \mathrm{J} \mathrm{mol}^{-1} \mathrm{~K}^{-1}\end{array}$ & $\gamma$ \\
\hline $\mathrm{TP}$ & 25 & 43.81 & 0.733 & -0.770 & 61.694 & 209.611 & 1.37 \\
& 35 & & 1.550 & -2.866 & & & \\
& 45 & & 3.508 & -4.962 & & & \\
$\mathrm{TF}$ & 25 & 54.20 & 0.841 & -0.431 & 68.717 & 232.039 & 1.51 \\
& 35 & & 1.888 & -2.751 & & & \\
& 45 & & 4.807 & -5.072 & & & \\
\hline
\end{tabular}

Calculated activation energies for the extraction process with $50 \%$ ethanol were $43.81 \mathrm{~kJ} \mathrm{~mol}^{-1}$ for TP and $54.20 \mathrm{~kJ} \mathrm{~mol}^{-1}$ for TF, respectively. These results indicated that the extraction rate was more sensitive to temperature in case of extraction of TF. By contrast, the extraction rate was less sensitive to temperature in case of extraction of TP. Values obtained for activation energies were comparable to these for temperature extraction coefficients. Similar results were observed for the extraction process of polyphenols with different solvents. For the extraction of polyphenols from grape seeds with $50 \%$ aqueous ethanol the value for activation energy was $1.10-7.70 \mathrm{~kJ} \mathrm{~mol}^{-1}$. ${ }^{39}$ For the polyphenols from grape seeds extracted with $60 \%$ methanol acidified with $\mathrm{HCl}$ the value obtained was $23 \mathrm{~kJ} \mathrm{~mol}^{-1} .{ }^{40}$ Determined activation energies for total polyphenols extraction with deionized water were $50.301 \mathrm{~kJ} \mathrm{~mol}^{-1}$ for dandelion, $51.316 \mathrm{~kJ} \mathrm{~mol}^{-1}$ for marigold, $56.958 \mathrm{~kJ} \mathrm{~mol}^{-1}$ for yarrow and $69.901 \mathrm{~kJ} \mathrm{~mol}^{-1}$ for chamomile. ${ }^{41}$

The equilibrium constant $(\mathrm{K})$ increased with increase in the temperature, indicating that the equilibrium concentration of phenolic compounds in extracts was also increasing. The positive enthalpy change indicated that the extraction process was endothermic and required external energy source during the extraction. ${ }^{42}$ The enthalpy in this study, was comparatively higher than those of total phenolics from hop studied by Paunović et al., ${ }^{43}$ total polyphenols from barley by Paunović et al., ${ }^{44}$ and flavonoids from Phyllanthus emblica by Krishnan and Rajan, ${ }^{45}$ which were in the range $\left(2.36-12.25 \mathrm{~kJ} \mathrm{~mol}^{-1}\right)$. This higher enthalpy could be attributed to the morphology of the plant materials influencing polyphenols extraction. ${ }^{20}$ The positive entropy values for the extraction of TP and TF from linen flowers using $50 \%$ ethanol were 209.611 and 232.039 $\mathrm{J} \mathrm{mol}^{-1} \mathrm{~K}^{-1}$. The entropy of the mixture increases due to the polyphenol molecules extraction. ${ }^{42}$ The positive values of the entropy change for the entire process was an indication that the process was irreversible, thus in line with the findings of Aman et al., ${ }^{46}$ Sulaiman et al. and ${ }^{42}$ Menkiti et al. ${ }^{20}$ The free energy values for the extraction of TP and TF were negative. This negative value was an indication that the process was feasible and spontaneous. The spontaneity of the TP and TF extraction from lined flowers were favoured with increasing extraction temperature. The Gibbs free energy change for the TP and TF extraction from linden flowers is similar to flavonoids from Phyllanthus emblica, ${ }^{45}$ hempseed oil by Kostić et al. ${ }^{21}$ and coconut oil by Sulaiman et al. ${ }^{42}$ which were in the range $\left(-0.48\right.$ to $\left.-5.17 \mathrm{~kJ} \mathrm{~mol}^{-1}\right)$ and lower than those for the total phenols extraction from hop. ${ }^{43}$

\section{Conclusions}

This study suggested that process parameters, such as concentration of extraction solvent, liquid-solid ratio, temperature and time extraction, influenced the content of TP and TF. The three kinetic models studied: Ponomaryov equation, film theory and the unsteady-state diffusion through the plant material all reasonably described TP and TF extraction from linden flowers as indicated by high $\mathrm{R}^{2}$, low RMS and S.D. values. The model based on the unsteady-state diffusion through the plant material gave the best fit, followed by Ponomatyov's model, and then the film theory model. The $\Delta \mathrm{G}^{\circ}, \Delta \mathrm{H}^{\circ}$ and $\Delta \mathrm{S}^{\circ}$ and values obtained for the TP and TF extraction indicated that the extraction process was spontaneous, irreversible, and endothermic, respectively.

\section{Acknowledgements}

Research in this paper is part of the project no. 451-03-68/ 2020-14/200124 financed by the Ministry of Education, Science and Technological Development of the Republic of Serbia.

\section{SORCID iDs}

M. Mitic:

S. Jankovic:

S. Mitic:

G. Kocic:

P. Maskovic:

orcid.org/0000-0002-1310-0540 orcid.org/0000-0003-3804-3682 orcid.org/0000-0003-3301-5981 orcid.org/0000-0003-2386-2466 orcid.org/0000-0001-9049-6932

\section{References}

1 P. Mašković, V. Veličković, S. Đurocić, M. Radojković, A. Cvetanović, J. Švarc-Gajić, M. Mitić and J. Vulić, Biological activity and chemical profile of Lavatera thuringiaca L. extracts obtained by different extraction approaches, Phytomedicine, 2018, 38, 118-124.

2 K. Radoglou, D. Dobrowolska, G. Spyroglou and V. Nicolescu, A review on the ecology and silviculture of limes (Tilia cordata Mill., Moench.) in Europe, Die Bodenkultur, 2009, 60(9), 9-19.

3 M. Blumenthal, A. Goldberg and S. Foster, Herbal Medicine - Expanded Commission E Monographs, American Botanical Council, Integrative Medicine Communications, Boston, MA, 2000, pp. 240-243.

4 M.K. Al-Essa, E.I. Mohammed, A. Yanal, Y.A. Shafagoj, U. Fatma and F.U. Afifi, Studies on the direct effects of the alcohol extract of Tilia cordata on dispersed intestinal smooth muscle cells of guinea pig, Pharm. Biol., 2007, 45 (3), 246-250.

5 C. Jaenicke, J. Gruenwald and T. Brendler, Handbuch Phytotherapie Stuttgart Wissenschaftliche Verlagsgesellschaft mbH, 2003, p. 329.

6 A. Behrens, N. Maie, H. Knicker and I. Koegel-Knaber, MALDI-TOF mass spectrometry and PSD fragmentation as means for the analysis of condensed tannin in plant leaves and needles, Phytochemistry, 2003, 62, 1159-1170.

7 E. Akyuz, H. Sahin, F. Islamoglu, S. Kolayli and P. Sandra, Evaluation of phenolic compounds in Tilia rubra subsp. Caucasica by HPLC-UV and HPLC-UV-MS/MS, Int. J. Food Prop., 2014, 17(2), 331-343.

8 M. Vidović, F. Morina, S. Milić and S. Veljović-Jovanovič, An improved HPLC-DAD method for simultaneously measuring phenolics in the leaves of Tilia platyphyllos and Ailanthus altissima, Bot. Serb., 2015, 39(2), 177-186.

9 G. Toker, M. Aslan, E. Yeşilada, M. Memişoğlu and S. Ito, Comparative evaluation of the flavonoid content in officinal Tiliae flos and Turkish lime species for quality assessment, J. Pharmaceut. Biomed., 2001, 26(1), $111-121$.

10 Y.Y. Thoo, S.K. Ho, J.Y. Liang, C.W. Ho and C.P. Tan, Effect of binary solvent extraction system, extraction time and extraction temperature on phenolic antioxidants and antioxidant capacity from mengkudu (Morinda citrifolia), Food Chem., 2010, 120, 290-295.

11 S.I. Mussatto, L.F. Ballesteros, S. Martins and J.A. Teixeira, Extraction of antioxidant phenolic compounds from spent coffee grounds, Sep. Purif. Technol., 2011, 83, 173-179.

12 S. Franquin-Trinquier, C. Maury, A. Baron, L.D. Meurlay and E. Mehinagic, Optimisation of the extraction of apple monomeric phenolics based on response surface methodology: comparaison of pressurised liquid-solid extraction and manual-liquid extraction, J. Food Compost. Anal., 2014, 34, 56-67.

13 V.L. Singleton and J. Rossi, Colorimetry of total phenolics with phosphomolybdic-phosphotungstic acid reagent, Am. J. Enol. Viticult., 1965, 16, 144-158.

14 C.C. Chang, M.H. Yang, H.M. Wen and J.C. Chern, Estimation of total 
flavonoid content in propolis by two complementary colorimetric methods, J. Food Drug. Anal., 2002, 10, 178-182.

15 Y. Gong, X. Lui, H. Wen-Hao, X. Hong-Gao, F. Yuan and Y.X. Gao, Investigation into the antioxidant activity and chemical composition of alcoholic extracts from defatted marigold (Tageteserecta L.) residue, Fitoterapia, 2012, 83, 481-489.

16 M. Alothman, R. Bhat and A.A. Karim, Antioxidant capacity and phenolic content of selected tropical fruits from Malaysia, extracted with different solvents, Food Chem., 2009, 115, 785-788.

17 M.N. Mitić, I.M. Souquet, M.V. Obradović and S.S. Mitić, Phytochemical profiles and antioxidant activities of Serbian table and wine grapes, Food Sci. Biotechnol., 2012, 21(6), 1619-1626.

18 S. Kitanović, D. Milenović and V.B. Veljković, Empirical kinetic models for the resinoid extraction from aerial parts of St. John's wort (Hypericum perforatum L.), Biochem. Eng. J., 2008, 41, 1-11.

19 B. Rahmanian, M. Pakizeh, S.A.A. Mansoori and R. Abedini, Application of experimental design approach and artificial neural network (ANN) for the determination of potential micellar-enhanced ultrafiltration process, J. Hazard. Mater., 2011, 187, 67-74.

20 M.C. Menkiti, C.M. Agu and T.K. Udeigwe, Extraction of oil from Terminalia catappa L: process parameter impacts, kinetics, and thermodynamics, Ind. Crops Prod., 2015, 77, 713-723.

21 M.D. Kostić, N.M. Joković, O.S. Stamenković, K.M. Rajković, P.S. Milić and V.B. Veljković, The kinetics and thermodynamics of hempseed oil extraction by n-hexane, Ind. Crops Prod., 2014, 52, 679-686.

22 A.K. Bucić, M. Planinić, S. Tomas, M. Bilić and D. Velic, Study of solid-liquid extraction kinetics of total polyphenols from grape seeds, J. Food Eng., 2007, 81(1), 236-242.

23 M.S.R. Alonso, E. Korta, A. Barranco and A.L. Berrueta, Pressurized liquid extraction for the determination of polyphenols in apple, J. Cromatogr. A, 2001, 933, 37-43.

24 B. Sultana, F. Anwar and M. Ashraf, Effect of extraction solvent/technique on the antioxidant activity of selected medicinal plant extracts, Molecules, 2009, 14, 2167-2180.

25 G. Spigno, L. Tramelli and D.M. De Faveri, Effects of extraction time, temperature and solvent on concentration and antioxidant activity of grape marc phenolics, J. Food Eng., 2007, 81(1), 200-208.

26 Z. Wissam, A.A. Nour, J. Bushra, N. Zein and D. Saleh, Extracting and studying the antioxidant capacity of polyphenols in dry linden leaves (Tilia cordata), J. Pharmacogn. Phytochem., 2017, 6(3), 258-262.

27 M. Radojković, Z. Zeković, S. Jokić and S. Vidović, Determination of optimal extraction parameters of mulberry leaves using response surface methodology (RMS), Rom. Biotechnol. Lett., 2012, 17, 7295-7308.

28 S. Jokić, D. Velić, M. Belić, A. Bucić-Kojić, M. Planinić and S. Tomas, Modelling of the process of solid-liquid extraction of total polyphenols from soybeans, Cyech. J. Food Sci., 2010, 28, 206-212.

29 M.A. Rostango, M. Palma and C.G. Barroso, Pressurised liquid extraction of isoflavones from soybeans, Anal. Chim. Acta, 2004, 522, 169-177.

30 V.D. Ponomaryov, Medicinal Herb Extraction, Medicina, Moscow, Russia, 1976.

31 R. Chirinos, H. Rogez, D. Campos, R. Pedreschi and Y. Larondelle, Optimisation of extraction conditions of antioxidant phenolic compounds from mashua (Tropaeolum tuberosum Ruíz \& Pavón ) tubes, Sep. Purif. Technol., 2007, 55, 217-225.

32 K.K. Chew, S.Y. Ng, Y.Y. Thoo, M.Z. Khoo, W.M. Wan Aida and C.W. Ho, Effect of ethanol concentration, extraction time and extraction temperature on the recovery of phenolic compounds and antioxidant capacity of Centella asiatica extracts, Int. Food Res. J., 2011, 18, 571-578.

33 M. Pinelo, J. Sineiro and M.J. Nunez, Mass transfer during continuous solid-liquid extraction of antioxidants from grape byproducts, J. Food Eng., 2006, 77(1), 57-63.

34 F. Gironi and V. Piemonte, Temperature and solvent effects on polyphenol extraction process from chestnut tree wood, Chem. Eng. Res. Des., 2011, 89, 857-862.

35 W. Vongsangnak, J. Gua, S. Chauvatcharin and J.J. Zhong, Towards efficient extraction on notoginsengsaponins from cultured cells of panaxnotoginseng, Biochem. Eng. J., 2004, 18(2), 115-120.

36 S.J. Kim, H.N. Murthy, E.J. Hahn, H.L. Lee and K.Y. Paek, Parameters affecting the extraction of ginsenosides from the adventitious roots of ginseng (Panax ginseng C.A. Meyer), Sep. Purif. Technol., 2007, 56(3), 401-406.

37 E. Akyuz, H. Şahin, F. Islamoglu, S. Kolayli and P. Sandra, Evaluation of phenolic compoundsin Tilia rubra subsp. Caucasica by HPLCUVand HPLC-UV-MS/MS, Int. J. Food Prop., 2014, 17(2), 331-343.

38 M. Vidović, F. Morina, S. Milić and S. Veljović-Jovanovič, An improved HPLC-DAD method for simultaneously measuring phenolics in the leaves of Tilia platyphyllos and Ailanthus altissima, Bot. Serb., 2015, 39(2), 177-186.

39 G. Toker, M. Aslan, E. Yeșlada, M. Memișoğlu and S. Ito, Comparative evaluation of the flavonoid content in officinal Tiliae flos and Turkish lime species for quality assessment, J. Pharmaceut. Biomed., 2001, 26(1), 111-121.

40 D.T. Veličković, D.M. Milenović, M.S. Ristić and V.B. Veljković, Ultrasonic extraction of waste solid residues from the Salvia sp. essential oil hydrodistillation, Biochem. Eng. J., 2008, 42, 97-104.

41 S. Meziane and H. Kadi, Kinetics and thermodynamics of oil extraction from olive cake, J. Am. Oil Chem. Soc., 2008, 85, 391-396.

42 A. Bucić-Kojić, M. Planinić, S. Tomas, M. Bilić and D. Velić, Study of solid-liquid extraction of total polyphenols from grape seeds, J. Food Eng., 2007, 81, 236-242.

43 V. Sant'Anna, A. Brandelli, L.D.F. Marczak and I.C. Tessaro, Kinetic modeling of total polyphenol extraction from grape marc and characterisation of the extracts, Sep. Purif. Technol., 2012, 100, 82-87.

44 A.J. Tušek, M. Benković, A. Belščak Cvitanović, D. Valinger, T. Jurina and J.G. Kljusurić, Kinetics and thermodynamics of the solid-liquid extraction process of total polyphenols, antioxidants and extraction yield from Asteraceae plants, Ind. Crops Prod., 2016, 91, 205-214.

45 S. Sulaiman, A.R. Abdul Aziz and M.K. Arova, Optimisation and modeling of extraction of solid coconut waste oil, J. Food Eng., 2013, $114,228-234$.

46 Đ. Paunović, S.S. Mitić, G.S. Stojanović, M.N. Mitić, B.T. Stojanović and M.B. Stojković, Kinetics of the solid-liquid extraction process of phenolic antioxidants and antioxidant capacity from hop (Humulus lupulus L.), Sep. Sci. Technol., 2015, 50, 1-7.

47 Đ. Paunović, S.S. Mitić, D.A. Kostić, M.N. Mitić, B.T. Stojanović and J.Lj. Pavlović, Kinetics and thermodynamics of the solid-liquid extraction process of total polyphenols from barley, Adv. Tech., 2014, $3(2), 58-63$.

48 R.Y. Krishan and K.S. Rajan, Influence of microwave irradiation on kinetics and thermodynamics of extraction of flavonoids from Phyllanthus emblica, Braz. J. Chem. Eng., 2017, 34, 885-899.

49 S. Amin, G. Hawash and S. El Diwani, Kinetics and thermodynamics of oil extraction from Jatropha curcas in aqueous acidic hexane solutions, J. Am. Sci., 2010, 6(11), 8. 